\title{
Female Sexual Response before and during Pregnancy
}

Siti Candra Windu Baktiyani ${ }^{1}$, Benediktus Arifin ${ }^{1}$, Mulyohadi Sungkono ${ }^{1}$, I WayanAgung Indrawan ${ }^{1}$, Edy Mustofa $^{2}$ andSamsul Bachri ${ }^{3}$

1. Social Obstetrics and Gynaecology Divisions, Faculty of Medicine, University of Brawijaya, Malang, East Java 65111, Indonesia

2. Deparment of Obstetrics \& Gynaecology, Bangil General Hospital, Pasuruan, East Java 67153, Indonesia

3. Deparment of Obstetrics \& Gynaecology, Kepanjen General Hospital, Malang, East Java 65163, Indonesia

\begin{abstract}
Objective: The aim of the research is to compare female sexual response before women got pregnant and during their pregnancy. The research also tries to relate the number of gravidity (primi or multigraviditiy) with sexual response during and before pregnancy. Method: PSRI (Modified Pregnancy Sexual Response Inventory) Questionnaires were filled individually by 124 pregnant women that attend to Antenatal Clinic in Saiful Anwar General Hospital, Malang, East Java, Indonesia. The data were taken during their Antenatal Care and if needed, a trained resident was available at any time to assist in fulfilling the questionnaire. The data then were presented descriptively and were analyzed using Wilcoxon Signed Ranked Test, McNemar Test, and Kolmogorov-smirnov test.Result: There were significant differences between sexual response before and during pregnancy in terms of level of sexual activity, sexual desire, orgasm frequency, pain during sexual activity, sexual activity initiation, husband's level of sexual activity $(P<0.000)$. There was no significant difference of primi or multigravidity compared to sexual response before and during pregnancy. Conclusion: There were decreases of level of sexual activity, sexual desire, frequency of orgasm of women, and level of sexual activity of the husbands during pregnancy compared to before pregnancy. Pain during sexual intercourse increased during pregnancy compared to before pregnancy. Sexuality in pregnancy is a sensitive and somehow taboo to be discussed during Antenatal Care, a specific-personal approach and counseling by well-trained health professional, in this case OB/GYN Specialist, is needed to be able to explore and manage any issue related to sexuality in pregnancy.
\end{abstract}

Key words: Female sexual response, pregnancy.

\section{Introduction}

Female sexuality is a complex process, which is medically coordinated by the neurological system, vascular, and endocrine. Furthermore, female sexuality is closely related to social aspects, religion, health status, personal experiences, and interpersonal relationships. The complexity of female sexuality increases when women become pregnant. Pregnancy is a complex period when physical and emotional changes during pregnancy that are also related to socio-cultural aspects will affect women's sexuality. Changes in sexuality during pregnancy include changes in sexual drive/sexual desire, changes related to physical and emotional aspects of pregnancy,

Corresponding author: Siti Candra Windu Baktiyani, Ph.D., OB/GYN Specialist, research fields: social obstetrics/gynecology, sexual and reproductive health. E-mail: yani_dr67@yahoo.com associated hormonal changes, and changes in sexual activity.

From one side sexual activity can lead to increased medical risk factor, but the other side, sexual activity can provide benefits for pregnancy and childbirth. The old generation of obstetricians prohibits sexual activity since the gestation of 6 weeks to 3 months or more before the expected delivery time [1]. This reasoning is based on the concept that sexual activity posses a potentially harmful effect of pregnancy on the uterus and cervix which are caused by prostaglandins in seminal fluid. A series of recent studies with larger samples and a stronger level of evidence reveal the opposite phenomenon of the risk of sexual intercourse/coitus on preterm pregnancy, spontaneous labor, the incidence of asymptomatic bacterial vaginosis, as well as its effect on the induction of labor [2, 3]. 
Many medical personnel feel less comfortable discussing sexuality during pregnancy, even in some cultures are said to be taboo in talking about sexual activity while pregnant. In some women, sociocultural and religious aspects made them uncomfortable in expressing the topic of sexual activity during pregnancy when dealing with doctors. This causes problems of sexuality during pregnancy often overlooked as part of the problem of comprehensive women's reproductive health.

Research related to comprehensive sexuality during pregnancy is still quite limited in Indonesia. Nonetheless, aspects of sexuality are an important aspect to receive attention in modern life today. This study seeks to open up new insights about the importance of attention to issues of sexuality in pregnancy. Aspects of sexuality in pregnant women are closely related to changes in sex drive, physical and emotional changes related to sexuality of pregnant women, hormonal influences on female sexuality and pregnancy, as well as changes in sexual activity during pregnancy.

This study is a cross-sectional study using a measuring instrument which has been standardized, namely the adaptation of PSRI (Pregnancy Sexual Response Inventory). This study will be descriptively uncovering pregnant women's sexual responses as well as analytically revealing the difference variable related to sexual response frequency of sexual intercourse, sexual drive, sexual quality, husband's perspective, sexual satisfaction, and orgasm, pain during sexual intercourse and sexual relations initiatives in pregnant women.

\section{Research Problems}

This study seeks to discuss issues related to sexual response in pregnant women compare to condition before pregnancy. In detail the problem of sexual response is expressed as follows:

Is there a significant difference between frequency of sexual activity during pregnancy and before pregnancy;

Is there a significant difference between the value of sexual activity during pregnancy and before pregnancy;

Is there a significant difference between sexual satisfaction during pregnancy and before pregnancy;

Is there a significant difference between frequency of orgasm during pregnancy and before pregnancy;

Is there a significant difference between the experience of pain during sexual activity during pregnancy and before pregnancy;

Is there a significant difference between the initiation of sexual activity during pregnancy and before pregnancy;

Is there a significant difference between the husband's value of sexual activity during pregnancy and before pregnancy;

Is there a significant difference between the statuses of gravid (prime or multi-gravid) on the frequency of sexual activity during pregnancy and before pregnancy.

\section{Research Methodology}

This is a comparative analytical study. The study was conducted at the Antenatal Care Outpatient Unit in Saiful Anwar Hospital Malang in the period February-April 2011. Selection of research subjects (sample) is by simple random sampling of pregnant women at antenatal care outpatient unit in Saiful Anwar Hospital, Malang in the period from February to April 2011. By using online sample size calculation by Raosoft and the average visit 150 new customers within 3 months, 95\% confidence level and the margin of error $(\alpha)=0.05$ and assuming the largest distribution of response samples $(P=0.5)$, then the number of samples obtained is minimum 109 subjects. In this study 124 subjects have been taken.

\subsection{Techniques of Data Collection}

Pregnant women's sexual response data were obtained by filling the questionnaire adaptation 
Inventory Pregnancy Sexual Response-PSRI conducted individually when the subject of cross-sectional studies do antenatal visit to Saiful Anwar Hospital Malang in the period from February to April 2011. Research questionnaire was attached to this research report.

\subsection{Data Analysis}

The collected data will be showed by descriptive analysis in a frequency distribution tables and a differential test. Hypothesis testing is done by non-parametric statistical where ordinal categorical data were analyzed statistically using the Wilcoxon Signed Rank Test and nominal data using the McNemar test. Hypothesis test for ordinal categorical data that are not paired is done by using Kolmogorov-Smirnov test. Overall statistical analysis is done using SPSS 17.0.

\section{Results and Discussion}

\subsection{Characteristics of Subjects}

Characteristics of the subjects of this study can be seen in the distribution table as in Table 1.

Most respondents (77.4\%) have high school education, which indicates that respondents are able to understand and fill out the questionnaire independently. It also allows respondents to have a wider horizon and to be more open-minded on the issue of sexuality that for the majority of women is still not open to talk about. Most respondents aged between 20-34 years (75.8\%) with the proportion of working and not working as well as prime and multi-gravid each balanced. It shows the distribution of respondents fairly evenly, so it is assumed in this study that the work factor and prime/multi-gravid statuses have spread equally or balanced.

Fig.1 shows each respondent characteristic.

\subsection{Changes in Frequency of Sexual Activity before and during Pregnancy}

To a question "Is the frequency of your sexual activity to be changed during this pregnancy?", two-thirds $(66.1 \%)$ revealed the frequency of sexual activity become more rare, steady (29.0\%) and only a

Table 1 Characteristic frequency percentage.

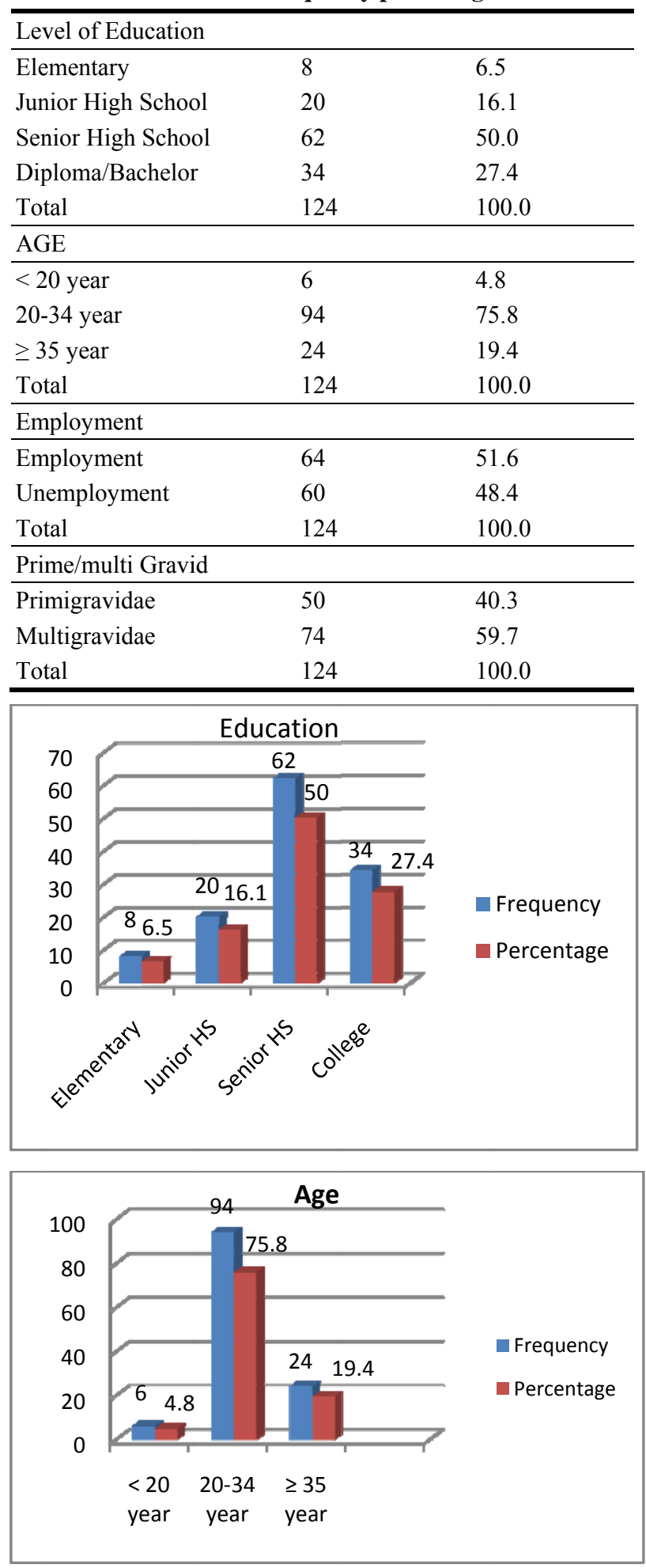

Fig. 1 Each respondent characteristic. 
few saying that the frequency becomes more frequent (4.8\%). Distribution of change in frequency of sexual activity can be seen in Table 2 .

Fig. 2 illustrates the frequency of activity before and during pregnancy.

The results of statistical tests with a one-sample $t$-test is a $P$-value $=0.000(<0.05)$. This suggests the existence of significant differences between the frequency of activity before and during pregnancy.

\subsection{The Value of Sexual Activity in Pregnancy and before Pregnancy}

To the same women (the paired variable) was asked about the value given to the quality of their sexual activity during pre-pregnancy and during pregnancy. This value is divided into an ordinal scale by dividing the value of 0-3 (or less), the value of 4-7 (enough), and the value of 8-10 (good). Distribution of the respondents' value of sexual activity can be seen in Table 3.

Graph of the value of sexual activity can be seen in Fig. 3.

There is an increased percentage of less value in woman before she was pregnant and during pregnancy (22.2\% increased). Besides, there is also a decreased in the percentage of good value from $21 \%$ before pregnancy to $3.2 \%$ during pregnancy. From a statistical test with Wilcoxon Signed Rank tests obtained $P$-value $=0.000(<0.05)$. This suggests the existence of significant differences the value of women's sexual activity before pregnancy and during pregnancy. It can be concluded in this study that pregnancy give an impairment of sexual activity significantly compared to before pregnancy.

\subsection{Sexual Satisfaction of Women During and before Pregnancy}

Sexual satisfaction of women during and before pregnancy in this study were divided into 3 ordinal scale, that is not satisfied, hesitation (between satisfied and dissatisfied) and satisfied. Distribution of female
Table 2 Frequency of activity before and during pregnancy.

\begin{tabular}{llll}
\hline & $\mathrm{F}$ & $\%$ & \\
\hline More rare & 82 & 66.1 & One sample $t$-test \\
Steady & 36 & 29.0 & $P=0.000$ \\
More often & 6 & 4.8 & \\
\hline
\end{tabular}

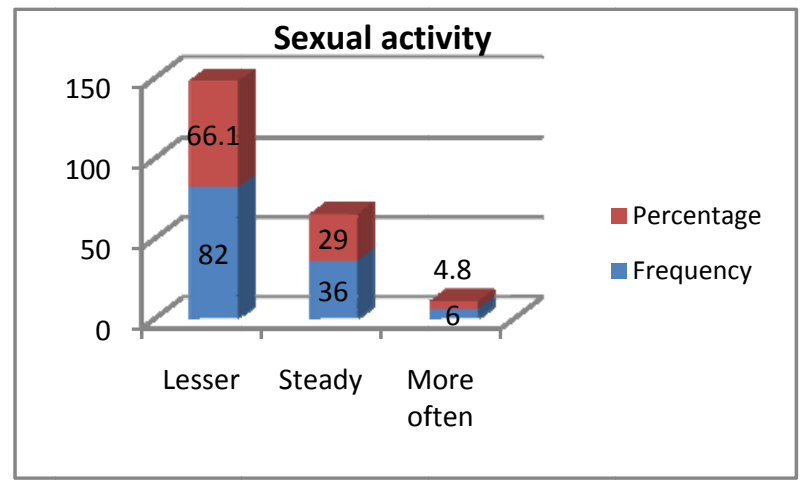

Fig. 2 The frequency of activity before and during pregnancy.

Table 3 Distribution of the respondents' value of sexual activity.

\begin{tabular}{|c|c|c|c|c|c|c|}
\hline \multirow{2}{*}{$\begin{array}{l}\text { Value of } \\
\text { sexual } \\
\text { activity }\end{array}$} & \multicolumn{3}{|c|}{$\begin{array}{c}\text { Before } \\
\text { pregnancy }\end{array}$} & \multicolumn{2}{|c|}{$\begin{array}{c}\text { During } \\
\text { pregnancy }\end{array}$} & \multirow{2}{*}{$\begin{array}{l}\text { Wilcoxon } \\
\text { Signed Rank } \\
\text { test } \\
P=0.000\end{array}$} \\
\hline & $\mathrm{F}$ & \multicolumn{2}{|c|}{$\%$} & $\mathrm{~F}$ & $\%$ & \\
\hline 0-3 (less) & 44 & \multicolumn{2}{|c|}{35.5} & 66 & 53.2 & \\
\hline $\begin{array}{l}4-7 \\
\text { (enough) }\end{array}$ & 54 & \multicolumn{2}{|c|}{43.5} & 54 & 43.5 & \\
\hline $8-10$ (good) & 26 & \multicolumn{2}{|c|}{21.0} & 4 & 3.2 & \\
\hline Total & 124 & \multicolumn{2}{|c|}{100.0} & 124 & 100.0 & \\
\hline \multirow[t]{2}{*}{$\begin{array}{r}140 \\
120 \\
100 \\
80 \\
60 \\
40 \\
20 \\
0\end{array}$} & 6 & & & & \multirow{2}{*}{\multicolumn{2}{|c|}{$\begin{array}{l}\text { 8-10 (Good) } \\
\text { 4-7 (Moderate) } \\
\text { 0-3 (Poor) }\end{array}$}} \\
\hline & $\begin{array}{l}\text { F } \\
\text { Befo } \\
\text { regn }\end{array}$ & $\begin{array}{l}\text { e } \\
\text { ncy }\end{array}$ & $\begin{array}{r}\mathrm{F} \\
\mathrm{D} \\
\text { pre }\end{array}$ & $\begin{array}{l}\text { ing } \\
\text { incy }\end{array}$ & & \\
\hline
\end{tabular}

Fig. 3 The value of sexual activity.

sexual satisfaction when she was pregnant and before pregnancy can be seen in Table 4 .

Graph of sexual satisfaction can be seen in Fig. 4.

Most women (91.9\%) were satisfied with their sexual life before pregnancy. However, there is an 
increasing percentage of women who experience sexual dissatisfaction during pregnancy than before pregnancy $(12.9 \%)$ and also decreased the percentage of women who are satisfied with her sexuality beforegetting pregnant than when pregnant (33.8\%). The results of statistical tests with Wilcoxon Signed Rank tests obtained $P$-value $=0.000(<0.05)$. This suggests the existence of significant differences the satisfaction of sexual life of women before pregnancy and when the woman is pregnant. It can be concluded in the study that pregnancy gives a significant decrease in sexual satisfaction.

\subsection{Sexual Drives of Pregnant Women and} Non-pregnant

The sexual drives of pregnant women andnon-pregnantin this study were divided into 3 ordinal scale that is bad, medium, fine. Distribution of women's sexual drive when she was pregnant and before pregnant can be seen in Table 5 .

Table 4 Distribution of female sexual satisfaction when she was pregnant and before pregnancy.

\begin{tabular}{|c|c|c|c|c|c|}
\hline \multirow{2}{*}{$\begin{array}{l}\text { Sexual } \\
\text { pleasure }\end{array}$} & \multicolumn{2}{|c|}{$\begin{array}{c}\text { Before } \\
\text { pregnancy }\end{array}$} & \multicolumn{2}{|c|}{$\begin{array}{c}\text { During } \\
\text { pregnancy }\end{array}$} & \multirow{2}{*}{$\begin{array}{l}\text { Wilcoxon } \\
\text { signed rank test } \\
P=0.000\end{array}$} \\
\hline & $\mathrm{F}$ & $\%$ & $\mathrm{~F}$ & $\%$ & \\
\hline $\begin{array}{l}\text { Not } \\
\text { satisfied }\end{array}$ & 4 & 3.2 & 20 & 16.1 & \\
\hline Hesitate & 6 & 4.8 & 32 & 25.8 & \\
\hline Satisfied & 114 & 91.9 & 72 & 58.1 & \\
\hline Total & 124 & 100.0 & 124 & 100.0 & \\
\hline
\end{tabular}

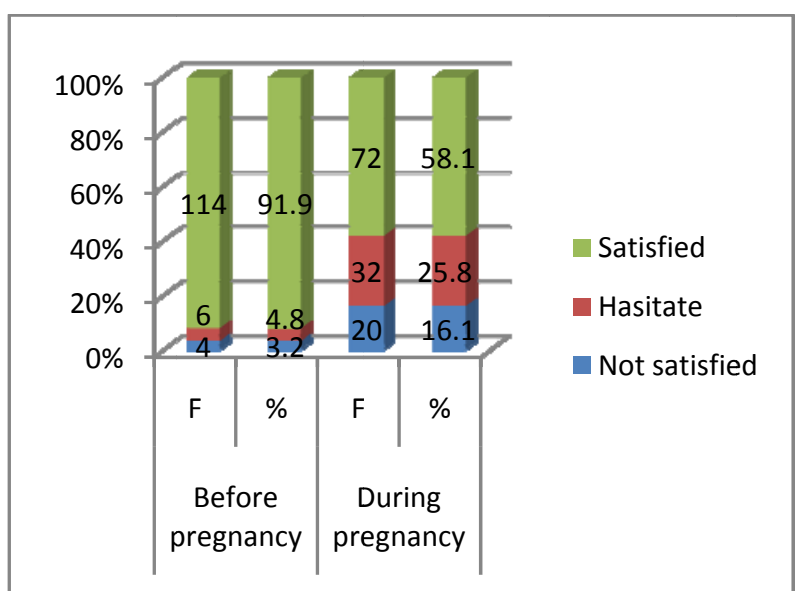

Fig. 4 Sexual satisfaction.
Graph of respondent's sexual drive can be seen in Fig. 5.

More than half (53.2\%) have a good sexual drive during pregnancy. There is a decrease in the percentage of the number of women who have a good sexual drive before pregnancy $(53.2 \%)$ than during pregnancy $(16.1 \%)$. The data above also indicate there is an increasing percentage of women who give the medium value before pregnancy $(43.5 \%)$ and when they were pregnant $(75.8 \%)$. The results of statistical tests with Wilcoxon Signed Rank tests obtained $P$-value $=0.000(<0.05)$. This suggests the existence of significant differences between the sexual drive of women before pregnancy and during pregnancy. It can be concluded in this study that pregnancy gives a significant decrease in sexual drive.

\subsection{The Frequency of Female Orgasm in Pregnancy and before Pregnancy}

The frequency of orgasm before becoming pregnant and in pregnant women in this study is divided into 3 ordinal scale that are never/rarely, sometimes, and often. Distribution of frequency of female orgasm when she was pregnant and before pregnant can be seen in Table 6

The frequency of respondents' orgasm can be seen in Fig. 6 .

Most of the women revealed that they sometimes have an orgasm while before pregnancy (67.7\%) andduring pregnancy $(79.0 \%)$. There is a growing percentage of the number of women whonever/rarely have an orgasm while before pregnancy $(3.2 \%)$ and during pregnancy (16.1\%). The data above also show that there is a decrease in the percentage of women who often experience orgasm while before pregnancy, i.e., $29.0 \%$ to only $4.8 \%$ during pregnancy. The results of statistical tests with Wilcoxon Signed Rank tests obtained $\mathrm{p}$-value $=0.000(<0.05)$. This suggests the existence of significant differences the frequency of female orgasm before pregnant and while pregnant. It 
Table 5 Distribution of women's sexual drive when she was pregnant and before pregnant.

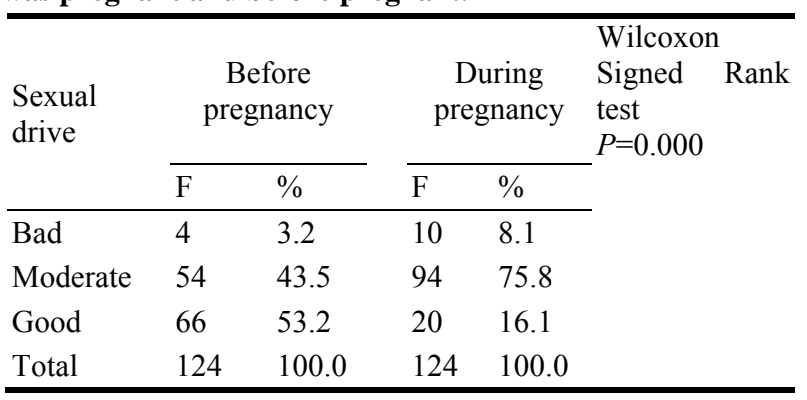

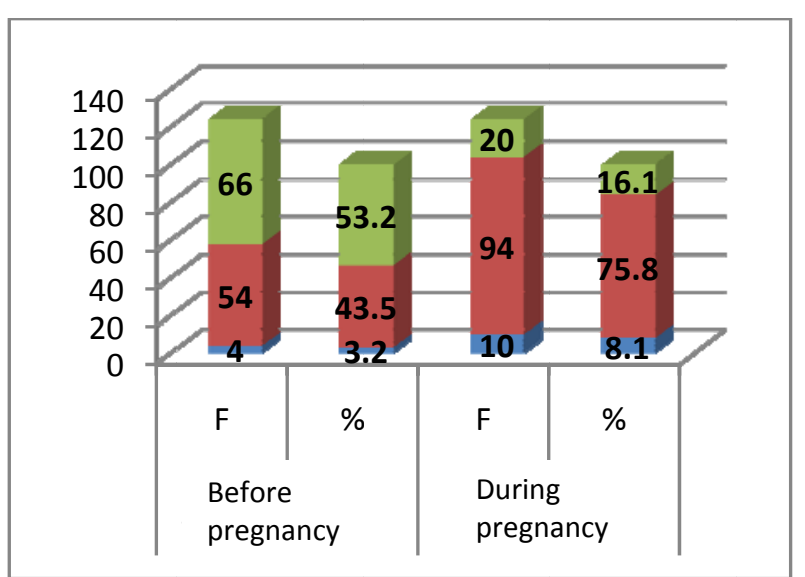

Fig. 5 Respondents' sexual drive.

Table 6 Distribution of frequency of female orgasm when she was pregnant and before pregnant.

\begin{tabular}{lllllll}
\hline \multirow{2}{*}{$\begin{array}{l}\text { Frequency of } \\
\text { orgasm }\end{array}$} & $\begin{array}{c}\text { Before } \\
\text { pregnancy }\end{array}$ & & $\begin{array}{c}\text { During } \\
\text { pregnancy }\end{array}$ & $\begin{array}{l}\text { Wilcoxon } \\
\text { signed rank } \\
\text { test } \\
\mathrm{P}=0.000\end{array}$ \\
\cline { 2 - 4 } \cline { 5 - 7 } & $\mathrm{F}$ & $\%$ & & $\mathrm{~F}$ & $\%$ & \\
\hline Never/Rare & 4 & 3.2 & & 20 & 16.1 & \\
Sometimes & 84 & 67.7 & & 98 & 79.0 & \\
Often & 36 & 29.0 & & 6 & 4.8 & \\
Total & 124 & 100.0 & & 124 & 100.0 & \\
\hline
\end{tabular}

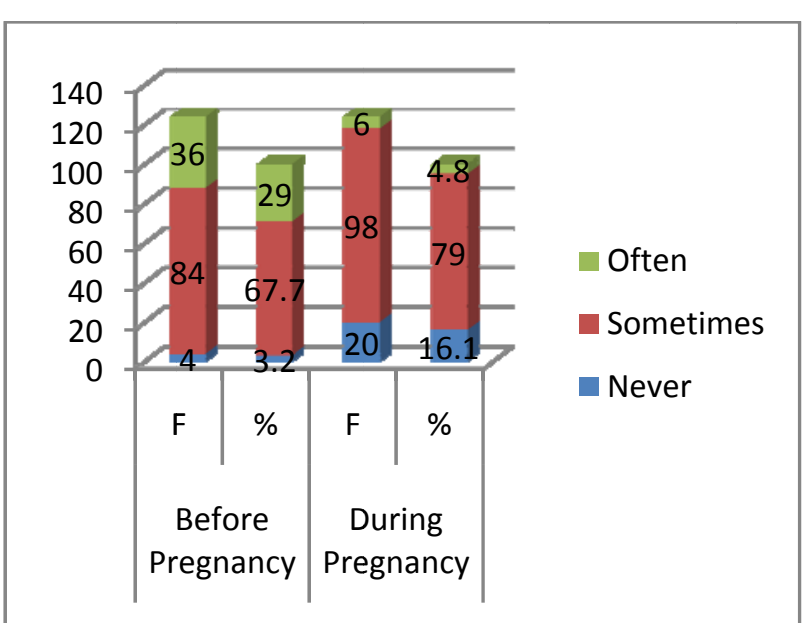

Fig. 6 Respondents' orgasm. can be concluded in this study that pregnancy gives a significant reduction in frequency of orgasm than before pregnancy.

\subsection{Pain during Intercourse in Women during Pregnancy and before Pregnancy}

Pain during intercourse in women during pregnancy and before pregnancy in this study is divided into two nominal scale that are painful and painless. Distribution of pain during sexual relations when she was pregnant and before pregnant can be seen in Table 7.

Most women (78.2\%) revealed no pain during intercourse before pregnancy. However, related to the time when she was getting pregnant, there is an increasing percentage of women who experience pain during intercourse compared to before she became pregnant $(32.2 \%)$ and decreased the percentage of women who previously did not experience any pain before pregnancy than during pregnancy (32.2\%).

Graph of the incidence of pain during intercourse can be seen in Fig. 7.

Table 7 Distribution of pain during sexual relations when she was pregnant and before pregnant.

\begin{tabular}{llclll}
\hline $\begin{array}{l}\text { Pain during } \\
\text { sexual } \\
\text { intercourse }\end{array}$ & $\begin{array}{c}\text { Before } \\
\text { pregnancy }\end{array}$ & & & $\begin{array}{c}\text { During } \\
\text { pregnancy }\end{array}$ & $\begin{array}{l}\text { McNemar } \\
\text { Test } \\
\mathrm{P}=0.000\end{array}$ \\
\cline { 2 - 3 } \cline { 5 - 6 } Yes & 27 & 21.8 & & 67 & 54.0 \\
No & 97 & 78.2 & & 57 & 46.0 \\
Total & 124 & 100.0 & & 124 & 100.0 \\
\hline
\end{tabular}

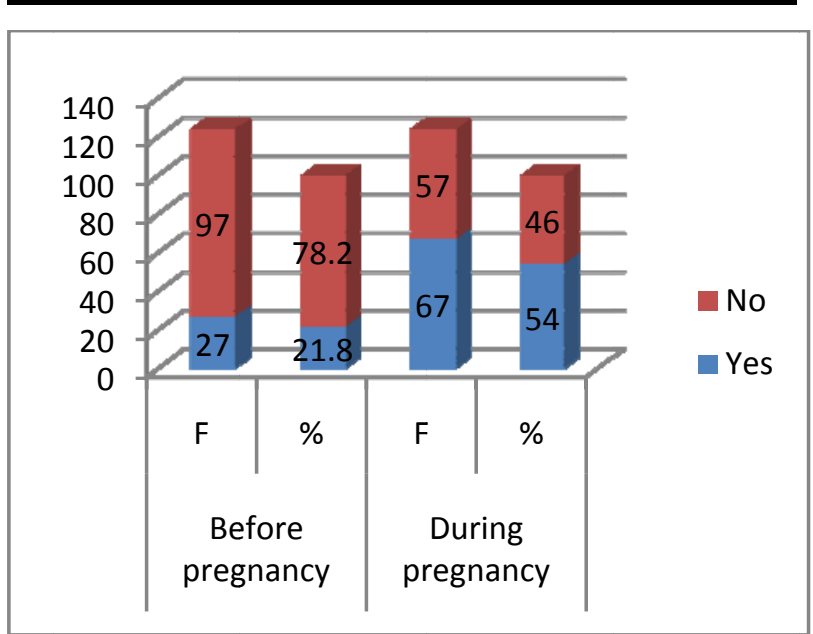

Fig. 7 The incidence of pain during intercourse. 
Statistical test results obtained with the McNemar test $P$-value $=0.000(<0.05)$. This suggests the existence of significant differences the occurrence of pain during intercourse in women before pregnancy and during pregnancy. It can be concluded in this study that pregnancy provides an increased incidence of pregnancy-related pain during sexual intercourse.

\subsection{Initiation of Sexual Activity in Women during} Pregnancy and before Pregnancy

Initiation of sexual activity in women during pregnancy and before pregnancy in this study isdivided into 3 ordinal scale that are forced in the absence of desire for sexual intercourse, the husband who usually initiates or invites, and spontaneously urge or desire for sexual intercourse. Distribution of initiation of sexual activity during pregnancy and before pregnancy can be seen in Table 8.

Initiation of sexual activity of respondents can be seen also in Fig. 8.

Most women (53.2\%) revealed that in the time before pregnancy, it was the husbands who started the initiation of sexual activity and almost half (45.2\%) they also had spontaneously willingness to initiate sexual activity, only slightly (1.6\%) which was start by forced to sexual intercourse and without the desire for sexual intercourse. However, when women getting pregnant there is an increase in presentations of forced and without the desire for sexual intercourse. Besides that, during pregnancy there is also an increase in percentage of sexual initiation from husband and a decreased spontaneous desire to start a sexual relationship. Statistical test results obtained with the McNemar test $P$-value $=0.000(<0.05)$. This suggests the existence of significant differences the initiation of sexual activity of women before pregnancy and during pregnancy.

\subsection{The Husbands' Value of Sexual Activity of Pregnant Woman and before Pregnant}

To the same women (the paired variable) were asked
Table 8 Distribution of initiation of sexual activity during pregnancy and before pregnancy.

\begin{tabular}{|c|c|c|c|c|c|}
\hline \multirow{2}{*}{$\begin{array}{l}\text { Initiation of } \\
\text { sexual activity }\end{array}$} & \multicolumn{2}{|c|}{$\begin{array}{l}\text { Before } \\
\text { Pregnancy }\end{array}$} & \multicolumn{2}{|c|}{$\begin{array}{l}\text { During } \\
\text { Pregnancy }\end{array}$} & \multirow{2}{*}{$\begin{array}{l}\text { Wilcoxon } \\
\text { Signed } \\
\text { Rank test } \\
\mathrm{P}=0.000\end{array}$} \\
\hline & $\mathrm{F}$ & $\%$ & $\mathrm{~F}$ & $\%$ & \\
\hline $\begin{array}{l}\text { Forced, } \\
\text { without desire }\end{array}$ & 2 & 1.6 & 12 & 9.7 & \\
\hline $\begin{array}{l}\text { Husband } \\
\text { initiates }\end{array}$ & 66 & 53.2 & 76 & 61.3 & \\
\hline Spontaneous & 56 & 45.2 & 36 & 29.0 & \\
\hline Total & 124 & 100.0 & 124 & 100.0 & \\
\hline
\end{tabular}

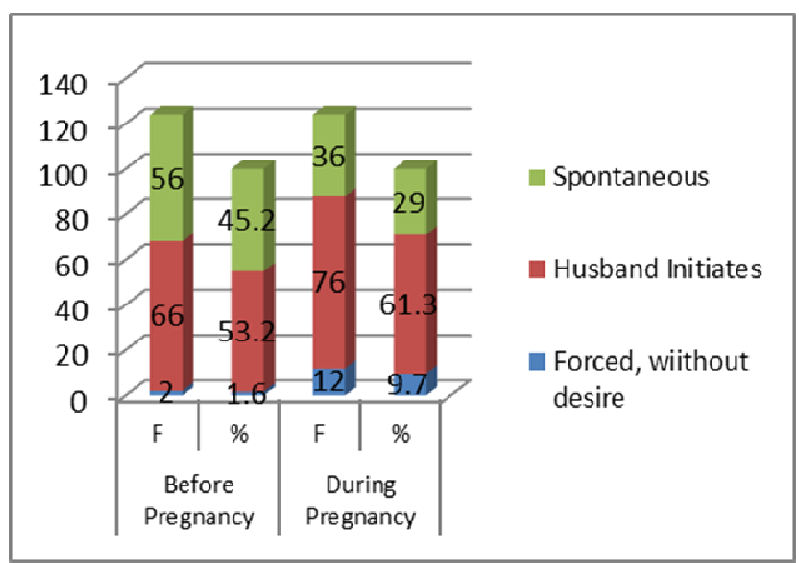

Fig. 8 Initiation of sexual activity of respondents.

about the value provided by their husbands the quality of sexual activity during pregnancy and before pregnancy. This value is divided into an ordinal scale by dividing the value of 0-3 (or less), the value of 4-7 (enough), and the value of 8-10 (good). Distribution of the husbands' value of sexual activity can be seen in Table 9.

The value of husbands' sexual activity can also be seen in Fig. 9.

There is an increase in the percentage value of less from husbands before pregnancy and during pregnancy $(25.8 \%$ increased). Besides that, it is also revealed the percentage decreases in the value of good from $33.9 \%$ before pregnancy to $8.1 \%$ during pregnancy. From a statistical test with Wilcoxon Signed Rank tests obtained $P$-value $=0.000(<0.05)$. This suggests the existence of significant differences the husband's value of sexual activity before pregnancy and during pregnancy. It can be concluded 
Table 9 Distribution of the husbands' value of sexual activity.

\begin{tabular}{|c|c|c|c|c|c|}
\hline \multirow{2}{*}{$\begin{array}{l}\text { Husbands' } \\
\text { value of } \\
\text { sexual } \\
\text { activity }\end{array}$} & \multicolumn{2}{|c|}{$\begin{array}{c}\text { Before } \\
\text { pregnancy }\end{array}$} & \multicolumn{2}{|c|}{$\begin{array}{l}\text { During } \\
\text { pregnancy }\end{array}$} & \multirow{2}{*}{$\begin{array}{l}\text { Wilcoxon } \\
\text { Signed } \\
\text { Rank Test } \\
P=0.000\end{array}$} \\
\hline & $\mathrm{F}$ & $\%$ & $\mathrm{~F}$ & $\%$ & \\
\hline $\begin{array}{l}0-3 \\
\text { (less) }\end{array}$ & 20 & 16.1 & 52 & 41.9 & \\
\hline 4-7 (enough) & 62 & 50.0 & 62 & 50.0 & \\
\hline 8-10 (good) & 42 & 33.9 & 10 & 8.1 & \\
\hline Total & 124 & 100.0 & 124 & 100.0 & \\
\hline
\end{tabular}

in this study that pregnancy gives a significant decreased of husband's value on sexual activity.

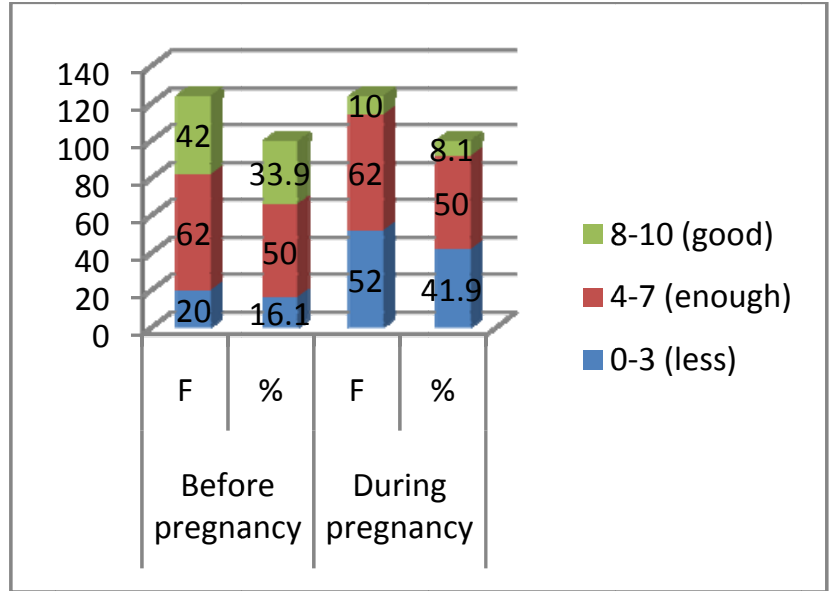

Fig. 9 The value of husbands' sexual activity.

Table 10 research results and statistical tests of each hypothesis of the study.

\begin{tabular}{|c|c|c|c|c|c|}
\hline \multicolumn{3}{|c|}{ Frequency of activity before and during pregnancy } & $\mathrm{F}$ & $\%$ & \multirow{5}{*}{$\begin{array}{l}\text { One sample } \\
\text { T-test } \\
P=0.000\end{array}$} \\
\hline \multicolumn{3}{|l|}{ More rare } & 82 & 66.1 & \\
\hline \multicolumn{3}{|l|}{ Steady } & 36 & 29.0 & \\
\hline \multicolumn{3}{|l|}{ More often } & 6 & 4.8 & \\
\hline \multicolumn{3}{|l|}{ Total } & 124 & 100.0 & \\
\hline \multirow{2}{*}{ The value of sexual activity } & \multicolumn{2}{|c|}{ Before pregnancy } & \multicolumn{2}{|c|}{ During pregnancy } & \multirow{5}{*}{$\begin{array}{l}\text { Wilcoxon signed rank } \\
\text { test } \\
P=0.000\end{array}$} \\
\hline & F & $\%$ & $\mathrm{~F}$ & $\%$ & \\
\hline 0-3 (Less) & 44 & 35.5 & 66 & 53.2 & \\
\hline 4-7 (Enough) & 54 & 43.5 & 54 & 43.5 & \\
\hline $8-10$ (Good) & 26 & 21.0 & 4 & 3.2 & \\
\hline \multirow{2}{*}{ Sexual drive } & \multicolumn{2}{|c|}{ Before pregnancy } & \multicolumn{2}{|c|}{ During pregnancy } & \multirow{5}{*}{$\begin{array}{l}\text { Wilcoxon signed } \\
\text { rank test } \\
P=0.000\end{array}$} \\
\hline & F & $\%$ & $\mathrm{~F}$ & $\%$ & \\
\hline Not satisfied & 4 & 3.2 & 20 & 16.1 & \\
\hline Hesitate & 6 & 4.8 & 32 & 25.8 & \\
\hline Satisfied & 114 & 91.9 & 72 & 58.1 & \\
\hline \multirow{2}{*}{ Frequency of orgasm } & \multicolumn{2}{|c|}{ Before pregnancy } & \multicolumn{2}{|c|}{ During pregnancy } & \multirow{5}{*}{$\begin{array}{l}\text { Wilcoxon signed } \\
\text { rank test } \\
P=0.000\end{array}$} \\
\hline & $\mathrm{F}$ & $\%$ & $\mathrm{~F}$ & $\%$ & \\
\hline Never/Rare & 4 & 3.2 & 20 & 16.1 & \\
\hline Sometimes & 84 & 67.7 & 98 & 79.0 & \\
\hline Often & 36 & 29.0 & 6 & 4.8 & \\
\hline \multirow{2}{*}{ Pain during sexual intercourse } & \multicolumn{2}{|c|}{ Before pregnancy } & \multicolumn{2}{|c|}{ During pregnancy } & \multirow{4}{*}{$\begin{array}{l}\text { Mcnemar Test } \\
P=0.000\end{array}$} \\
\hline & $\mathrm{F}$ & $\%$ & $\mathrm{~F}$ & $\%$ & \\
\hline Yes & 27 & 21.8 & 67 & 54.0 & \\
\hline No & 97 & 78.2 & 57 & 46.0 & \\
\hline \multirow{2}{*}{ Initiation of sexual activity } & \multicolumn{2}{|c|}{ Before pregnancy } & \multicolumn{2}{|c|}{ During pregnancy } & \multirow{5}{*}{$\begin{array}{l}\text { Wilcoxon signed } \\
\text { rank test } \\
P=0.000\end{array}$} \\
\hline & $\mathrm{F}$ & $\%$ & $\mathrm{~F}$ & $\%$ & \\
\hline Forced, without desire & 2 & 1.6 & 12 & 9.7 & \\
\hline Initiates from the husbands & 66 & 53.2 & 76 & 61.3 & \\
\hline Spontaneous & 56 & 45.2 & 36 & 29.0 & \\
\hline \multirow{2}{*}{ Husbands'value of sexual activity } & \multicolumn{2}{|c|}{ Before pregnancy } & Duri & & \multirow{5}{*}{$\begin{array}{l}\text { Wilcoxon signed } \\
\text { rank test } \\
P=0.000\end{array}$} \\
\hline & $\mathrm{F}$ & $\%$ & $\mathrm{~F}$ & $\%$ & \\
\hline 0-3 (Less) & 20 & 16.1 & 52 & 41.9 & \\
\hline 4-7 (Enough) & 62 & 50.0 & 62 & 50.0 & \\
\hline $8-10$ (Good) & 42 & 33.9 & 10 & 8.1 & \\
\hline
\end{tabular}


4.10 Differences of the Frequency of Sexual Intercourse Related to Gravidity during Pregnancy and before Pregnancy

Primigravidae and multigravidae were asked about the frequency of sexual intercourse during the pre-pregnancy period and during pregnancy. The frequency of sexual intercourse is divided into more rarely, steady and more frequently. Both variables are then analyzed by Kolmogorov-Smirnov statistical test, to test whether there is a difference between independent 3 ordinal scales and 2 nominal scales.

From the statistical tests with Kolmogorov-Smirnov obtained significance $P$-value $=0.080(>0.05)$. This shows no significant difference from the status of prime and multigravidae to frequency of sexual intercourse before and during pregnancy. It can be concluded in this study that the status of prime and multigravidae has no effect on the frequency of sexual intercourse before and during pregnancy.

Summary of statistical tests of each hypothesis of the study can be seen in Table 10 .

\section{Conclusions}

In conclusion, there were decreases of level of sexual activity, sexual desire, frequency of orgasm of women, and level of sexual activity of the husbands during pregnancy compared to before pregnancy. Pain during sexual intercourse increased during pregnancy compared to before pregnancy. In addition, sexuality in pregnancy is a sensitive and somehow taboo to be discussed during Antenatal Care in Indonesia, a specific-personal approach and counselling by well-trained health professional. In this case, OB/GYN Specialist is needed to be able to explore and manage any issue related to sexuality in pregnancy.

\section{References}

[1] Perkins,R.P. 1984. Sexuality during pregnancy. Clinical Obstetrics and Gynecology. Vol.27(3). P.706-716

[2] Kavanag, J., Kelly, A.J., Thomas, J. 2008. Sexual intercourse for cervical ripening and induction of labour. Cochrane Database of Systematic Review. Issue 4.

[3] Tan, P.C., Yow, C.M., Omar, S.Z. 2009. Coitus and orgasm at term: effect on spontaneous labour and pregnancy outcome. Singapore Medical Journal. Vol.50(11)p.1062-67. 